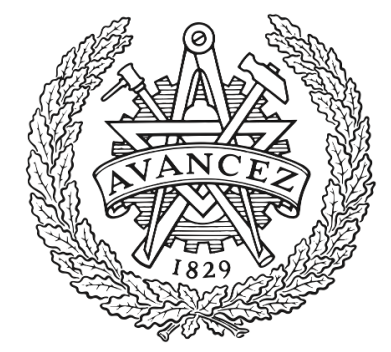

CHALMERS

UNIVERSITY OF TECHNOLOGY

\title{
DNA-Binding Properties of Amidine-Substituted Spiropyran Photoswitches
}

Downloaded from: https://research.chalmers.se, 2023-04-26 09:36 UTC

Citation for the original published paper (version of record):

Hammarson, M., Nilsson, J., Li, S. et al (2014). DNA-Binding Properties of Amidine-Substituted

Spiropyran Photoswitches. Chemistry - A European Journal, 20(48): 15855-15862.

http://dx.doi.org/10.1002/chem.201405113

N.B. When citing this work, cite the original published paper. 


\title{
DNA-Binding Properties of Amidine Substituted
}

\section{Spiropyran Photoswitches}

\author{
Martin Hammarson, Jesper R. Nilsson, Shiming Li, Per Lincoln and Joakim Andréasson* \\ Department of Chemical and Biological Engineering, Physical Chemistry, Chalmers \\ University of Technology, 41296 Göteborg, Sweden
}

E-mail: a-son@chalmers.se

\begin{abstract}
Two amidine substituted spiropyran derivatives have been characterized with respect to the DNA-binding properties over a broad $\mathrm{pH}$-interval. The two derivatives differ in the number of positive charges. By varying the $\mathrm{pH}$, the protonation state of the derivatives is also changed, allowing for additional variations in the charge distribution. We show that the closed spiro isomer does not bind for any of the two derivatives, whereas the open merocyanine forms bind both in the protonated and in the non-protonated state, but with dramatically different binding constants. Flow oriented LD measurements also show that there are differences in the binding modes between the various forms. We rationalize these differences in terms of structure and charge distribution.
\end{abstract}

\section{Introduction}

The use of photochromic molecules (molecular photoswitches) in bio-related contexts has been identified as a means to gain spatiotemporal control of drug action. ${ }^{[1-6]}$ Given that only one isomeric form of the photoswitch is biologically active, light can be used as a trigger to 
decide when and where the molecule is to be converted to the relevant isomer, allowing for a locally induced effect. When the target biomolecule is DNA the focus has been to control small molecule interactions. ${ }^{[7-8]}$ Since most of the DNA-associated intracellular processes could be inhibited by a molecule with a high DNA-binding affinity, an externally controlled non-invasive stimulus is highly desired, as it could reduce undesired side effects in applications such as chemotherapeutics. With this as the inspiration, studies aiming at photocontrolled DNA-binding have recently been presented. ${ }^{[9-19]}$ Among these, derivatives from several different photochromic families have been used. ${ }^{[9-10,13-18]}$ Our main focus has been on spiropyran photoswitches ${ }^{[9,14,20-22]}$ as the pronounced structural changes involved in the isomerization process makes them excellent candidates for the abovementioned purpose (see structures 1-4 and the isomerization pathways shown in Scheme 1). ${ }^{[9,14]}$ The colorless spiro (SP) form consists of two perpendicularly oriented heterocycles joined at the spiro carbon, resulting in a bulky non-planar structure. Typically, structures like these are not optimal for strong interactions with DNA. UV-induced isomerization to the colored merocyanine (MC) form results in a planar, aromatic, and polycyclic structure - features that are well known to facilitate DNA-binding by intercalation. ${ }^{[23]}$ Moreover, positive charges are essential in assisting DNA-binding by electrostatic attraction to the negatively charged phosphate backbone. ${ }^{[23]}$ The most likely of the spiropyran forms shown in Scheme 1 to bind to DNA would therefore be $\mathrm{MCH}^{+}$, formed by protonation of the phenolate oxygen of the $\mathrm{MC}$ isomer. Indeed, we have shown that for the 6-nitro and the 6-cyano versions $\mathbf{3}$ and $\mathbf{4}$ shown in Scheme 1, $\mathrm{MCH}^{+}$is the exclusive DNA-binder, and the preferred binding mode is intercalation. ${ }^{[9,}{ }^{14]}$ It is interesting to note that the single net-positive charge from the aminopropyl-derived "tail" attached to the indolenium nitrogen of $\mathbf{3}$ and $\mathbf{4}$ is not sufficient to make the geometrically well-suited MC structure intercalate between the base-pairs without the addition of an extra positive charge to form the $\mathrm{MCH}^{+}$dication. Hence, the charge 
distribution is strongly dictating whether or not DNA-binding occurs. In this respect, both the substitution pattern of permanently positive charged groups and the $\mathrm{p} K_{\mathrm{a}}$-value of the phenolic oxygen come into play. In the light of this, we have synthesized and characterized the DNAbinding properties of two novel spiropyran derivatives with differences in both the substitution pattern and the $\mathrm{p} K_{\mathrm{a}}$-value. A 4-state model has been used to quantitatively account for the difference in binding affinity between the $\mathrm{MC}$ and the $\mathrm{MCH}^{+}$forms, and qualitative arguments are used to explain these differences in terms of structure and charge distribution.

\section{Results and Discussion}

The primary objective of this work has been to investigate in detail the DNA-binding properties of spiropyran derivatives 1 and 2 shown in Scheme 1. Both compounds have an amidine substituent in the 6-position of the benzopyran moiety, whereas $\mathbf{1}$ has a methyl group and 2 has a quaternary aminopropyl group attached to the indoline nitrogen. In addition to assuring good water solubility, the main reasons for the choice of substitution patterns are the following: I) The amidine substituent was chosen due to its positive charge. It is also common to several well-known DNA-binding molecules, ${ }^{[23-25]}$ and we envisioned that the introduction of this group would assist in the binding of the non-protonated MC form. In addition, the electron withdrawing properties are such that it allows for a sufficient thermal stability of the $\mathrm{MC}$ forms at the same time as it positions the $\mathrm{p} K_{\mathrm{a}}$-value of the para phenolic $-\mathrm{OH}$ group in a region such that both $\mathrm{MC}$ and $\mathrm{MCH}^{+}$can be studied, while maintaining an intact structure of the DNA double helix ( $\mathrm{pH}$ between ca. 5 and 9, vide infra). $\left.{ }^{[26-27]} \mathrm{II}\right)$ The substituent on the indoline nitrogen was varied as to change the (net) charge of the SP and MC isomers between +1 (methyl group, 1) and +2 (quaternary aminopropyl group, 2). Interestingly, the choice of 
indoline substituent is influencing the $\mathrm{p} K_{\mathrm{a}}$-value of the relatively remote phenolic oxygen (vide infra).

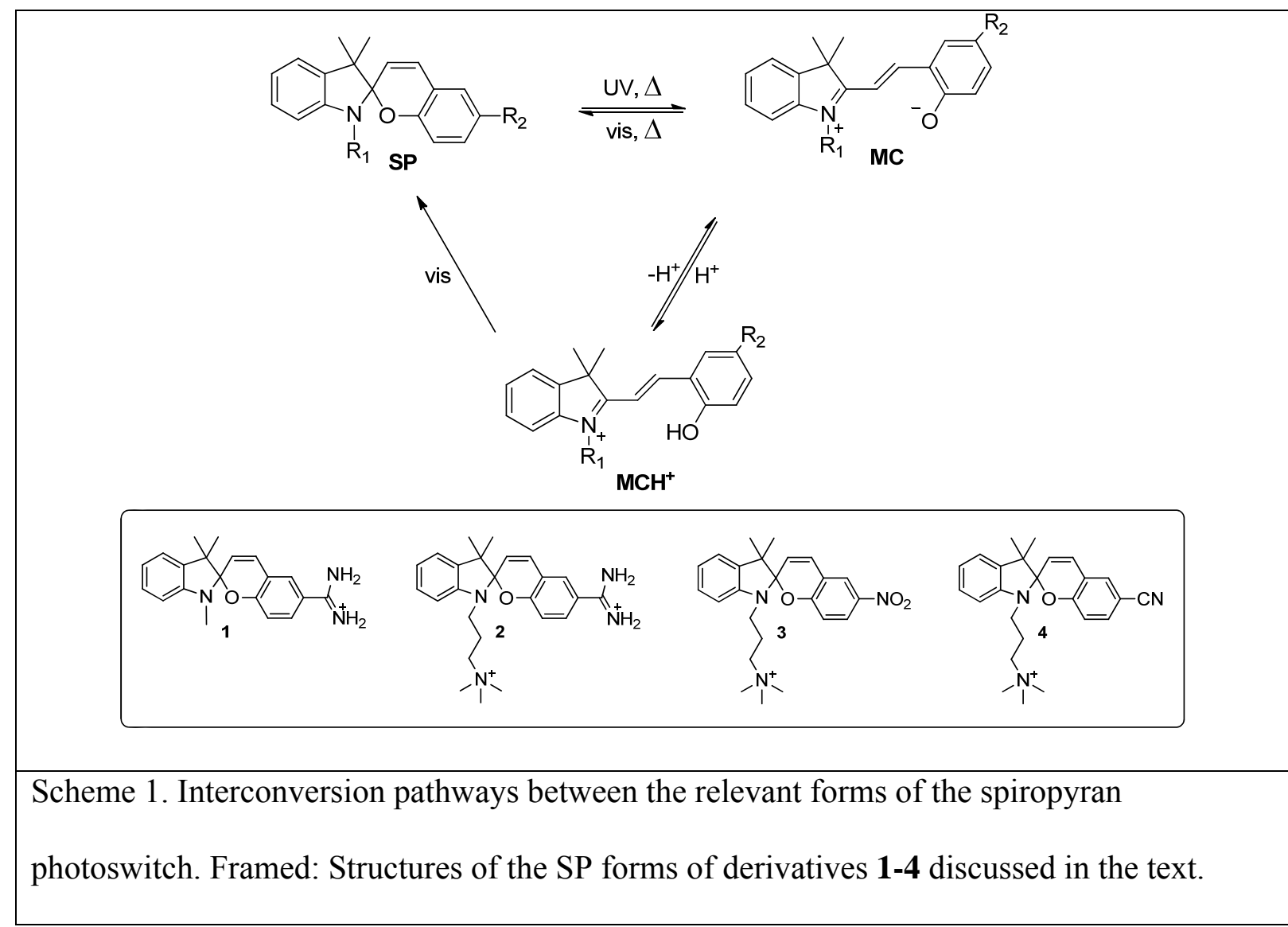

The sections below are organized as follows: First, the thermal and photoinduced isomerization processes in aqueous solution are described, together with the corresponding absorption spectra of the relevant forms. Second, the results from UV/vis absorption titrations between $\mathrm{pH} 5$ and $\mathrm{pH} 9$ are presented. Here, it is shown that the SP isomer is not significantly attracted to DNA, whereas the UV generated $\mathrm{MC}$ and $\mathrm{MCH}^{+}$forms of both $\mathbf{1}$ and $\mathbf{2}$ do bind to the double helix, albeit with substantially different binding constants. A 4-state model is used to account for the correlation between the $\mathrm{p} K_{\mathrm{a}}$-values and the binding constants in the corresponding protonation states. Finally, the binding modes of the different forms of $\mathbf{1}$ and $\mathbf{2}$ are investigated by flow-oriented linear dichroism (LD), and the results shows that the 
variations in structure and charge distribution are reflected also in the preferred mode of binding.

General behavior: The relevant forms of 1 and 2 are shown in Scheme 1 together with the corresponding interconversion pathways, and the absorption spectra in aqueous solutions are displayed in Figure 1.

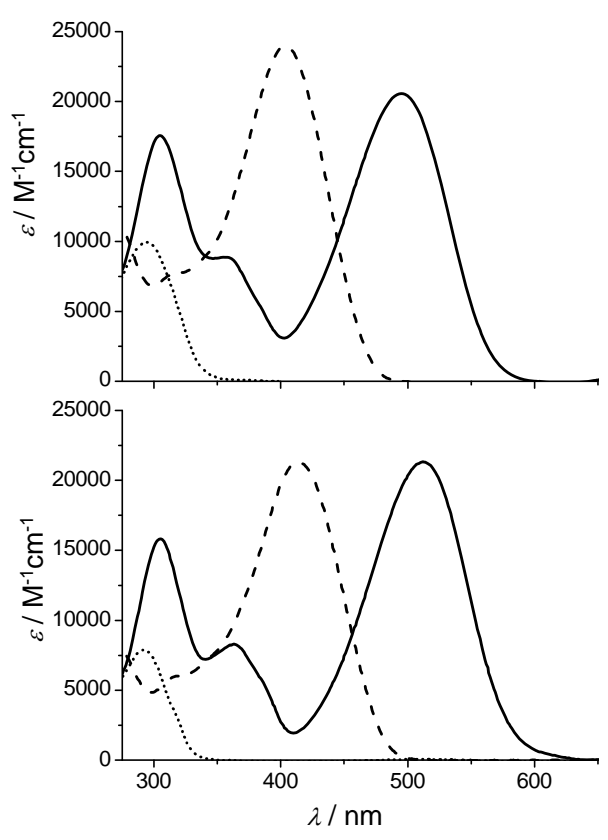

Figure 1. Absorption spectra of the SP (dotted line), $\mathrm{MC}$ (solid line), and the $\mathrm{MCH}^{+}$(dashed line) of $\mathbf{1}$ (top) and $\mathbf{2}$ (bottom) in aqueous solutions.

The conversion of the closed spirocyclic SP isomer to the open MC isomer is induced by UV exposure, whereas the reverse process is triggered by visible light. ${ }^{[28]}$ After isomerization with $\lambda=254 \mathrm{~nm}$ UV light the photostationary distribution $[\mathrm{SP}] /[\mathrm{MC}]$ is ca. $30 / 70$ and $15 / 85$ for $\mathbf{1}$ and 2, respectively, and the reverse isomerization using broadband visible light $(\lambda>450 \mathrm{~nm})$ converts both derivatives into $100 \%$ of the SP form. The yields for the isomerization 
reactions $\mathrm{SP} \rightarrow \mathrm{MC}$ are 0.02 for both 1 and 2, whereas the yields for the reverse reactions MC $\rightarrow \mathrm{SP}$ are 0.014 and 0.036 , respectively. The uncertainties in the isomerization yields are estimated to $\pm 50 \%$. In organic solvents, the $[\mathrm{SP}] /[\mathrm{MC}]$ ratio is virtually $100 / 0$ at thermal equilibrium. In aqueous solution, however, the zwitterionic MC isomer is substantially stabilized by the polar milieu. Hydrogen bonding has also been suggested to contribute to the MC form stabilization. ${ }^{[29]}$ This results in a shift of the thermal equilibrium position toward the MC side. For 1, the equilibrium is established with a time constant of 5 hours at room temperature, and the composition is ca. 20/80 [SP]/[MC]. For 2, the corresponding numbers are 1 hour and 85/15. Subsequent hydrolytic degradation of MC is observed, ${ }^{[30]}$ but on a much longer time scale (ca. 10 times slower compared to the thermal equilibrium establishment). ${ }^{[31-}$ ${ }^{32]}$ Upon acidification, protonation of the MC phenolate oxygen leads to the formation of $\mathrm{MCH}^{+}$with $\mathrm{pK} \mathrm{a}_{\mathrm{a}}$-values of 5.2 and 4.8 for $\mathbf{1}$ and $2 .{ }^{[33]}$ While this form is readily converted to SP using visible light, the corresponding thermal conversion is not observed. A comprehensive characterization of the thermal and photoinduced reactions of similar spiropyran derivatives in aqueous solution has recently been reported. ${ }^{[31]}$

DNA-binding properties of the SP isomer: To investigate if 1 SP and 2SP bind to DNA, absorption spectra were recorded before and after addition of large excess of salmon-sperm DNA at $\mathrm{pH}$ 7. The samples were continuously irradiated by visible light to suppress thermal formation of the MC isomers. The results are shown in Figure 2. 


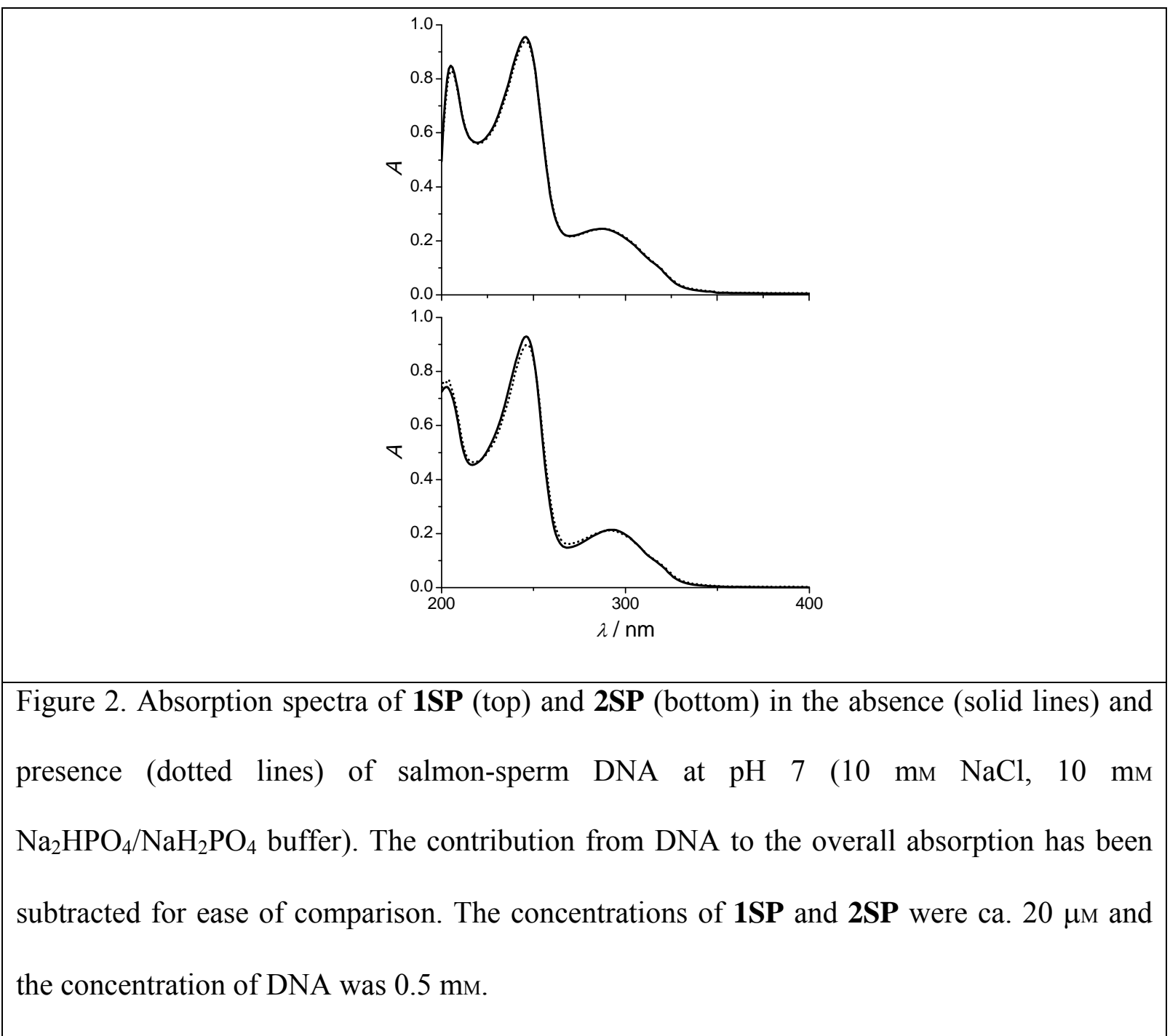

Since 1SP and 2SP absorb in a spectral region shared with DNA, the DNA signal has been subtracted for ease of comparison. There are no or very small effects on the absorption spectra after DNA addition, even at high concentration $(0.5 \mathrm{~mm})$. This clearly shows that there are no or only very weak interactions between the SP isomers and DNA, both for $\mathbf{1}$ and 2. This conclusion has been drawn also for similar spiropyran derivatives previously studied in our laboratory (3 and $\mathbf{4}$ in Scheme 1). ${ }^{[9,14]}$ It is worth noticing that the most pronounced (although minute) spectral changes occur for 2SP that comes with two positive charges. Non-specific electrostatic interactions are likely to explain these changes, but the effect is still too small to allow for any quantitative treatment. 
DNA-binding properties of the $\mathrm{MC}$ and $\mathrm{MCH}^{+}$forms: DNA titrations were performed between $\mathrm{pH} 5$ and $\mathrm{pH} 9$ on samples of $\mathbf{1}$ and $\mathbf{2}$ after $\mathrm{UV}$-induced isomerization to the MC and the $\mathrm{MCH}^{+}$forms (their relative concentrations depending on the $\mathrm{pH}$ ). The results are displayed in Figure 3 (for $\mathbf{1} \mathbf{M C} / \mathbf{1} \mathbf{M C H} \mathbf{C H}^{+}$) and Figure $4\left(\right.$ for $\mathbf{2} \mathbf{M C} / \mathbf{2} \mathbf{M C H} \mathbf{H}^{+}$). The overall trends are the same for $\mathbf{1}$ and $\mathbf{2}$ :

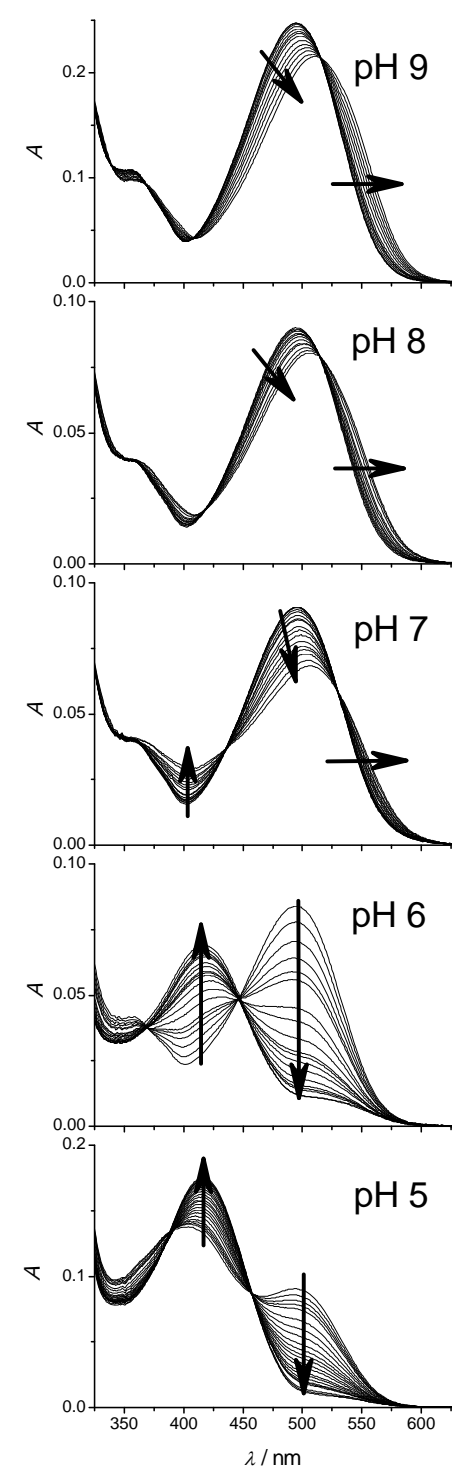

Figure 3. Absorption titration spectra of $\mathbf{1 M C} / \mathbf{1} \mathbf{M C H} \mathbf{H}^{+}$at $\mathrm{pH} 5$ to $\mathrm{pH}$ 9. The total concentration of $\mathbf{1 M C}+\mathbf{1} \mathbf{M C H}{ }^{+}$was kept below $15 \mu \mathrm{M}$ while the salmon-sperm DNA 
concentration was varied from $0 \mathrm{~mm}$ to ca. $1 \mathrm{~mm}$ at each $\mathrm{pH}$. The solutions contained $10 \mathrm{~mm}$ $\mathrm{NaCl}$ and $10 \mathrm{~mm} \mathrm{Na} 2 \mathrm{HPO}_{4} / \mathrm{NaH}_{2} \mathrm{PO}_{4}$ buffer.

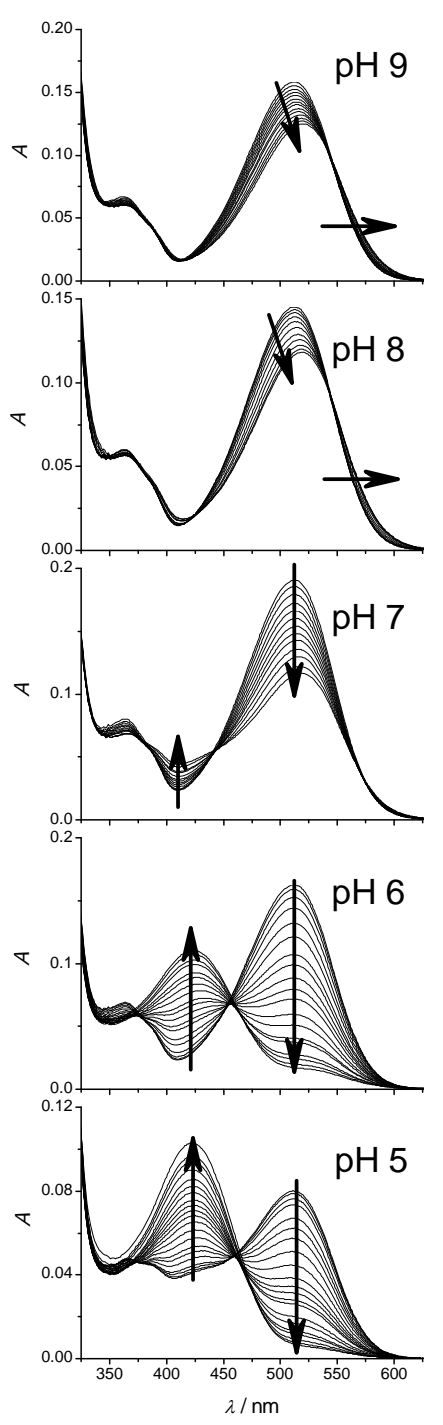

Figure 4. Absorption titration spectra of $\mathbf{2} \mathbf{M C} / \mathbf{2} \mathbf{M C H} \mathbf{H}^{+}$at $\mathrm{pH} 5$ to $\mathrm{pH}$ 9. The total concentration of $\mathbf{2 M C}+\mathbf{2} \mathbf{M C H}^{+}$was kept below $15 \mu \mathrm{M}$ while the salmon-sperm DNA concentration was varied from $0 \mathrm{~mm}$ to ca. $1 \mathrm{~mm}$ at each $\mathrm{pH}$. The solutions contained $10 \mathrm{~mm}$ $\mathrm{NaCl}$ and $10 \mathrm{~mm} \mathrm{Na} 2 \mathrm{HPO}_{4} / \mathrm{NaH}_{2} \mathrm{PO}_{4}$ buffer. 
At $\mathrm{pH} 9$, which is around $4 \mathrm{pH}$ units higher that the $\mathrm{p} K_{\mathrm{a}}$-value of the phenolic oxygen of $\mathbf{1 M C H}^{+}$and $2 \mathbf{M C H}^{+}$in solution, virtually $100 \%$ of the $\mathrm{MC} / \mathrm{MCH}^{+}$population is in the $\mathrm{MC}$ form before the addition of DNA. This is confirmed by the absence of spectral features from $\mathrm{MCH}^{+}$in the spectra $\left(\lambda_{\max }\right.$ at $403 \mathrm{~nm}$ and $414 \mathrm{~nm}$ for $\mathbf{1} \mathbf{M C H}{ }^{+}$and $\mathbf{2} \mathbf{M C H} \mathbf{H}^{+}$, respectively). The only spectral changes that occur upon DNA titration are a gradual red-shift and a decrease in the absorption of the non-protonated MC forms at around $500 \mathrm{~nm}$. This clearly signals that DNA-binding occurs for 1MC and 2MC. We refer to these species as 1MC@DNA and 2MC@DNA. Moreover, the DNA-binding is fully reversible by the use of visible light that isomerizes the bound $\mathrm{MC}$ isomers to the non-binding SP isomers. This is true also for all other $\mathrm{pH}$-values described below.

At $\mathrm{pH} 7$ and $\mathrm{pH} 8$, the concentration of $\mathbf{1} \mathbf{M C} \mathbf{C H}^{+}$and $\mathbf{2} \mathbf{M C H} \mathbf{H}^{+}$is again virtually zero before DNA is added. However, with increasing amount of DNA, the absorption is increasing in the wavelength regions where the majority of the absorption is ascribed to the protonated species. The red-shift in the absorption of the 1MC and 2MC isomers at around $500 \mathrm{~nm}$ is still observed, albeit less pronounced compared to $\mathrm{pH} 9$.

At $\mathrm{pH}$ 6, the presence of $\mathbf{1} \mathbf{M C H}{ }^{+}$is obvious even in the absence of DNA (due to the increase in the absorption around $400 \mathrm{~nm}$ ), whereas the concentration of $\mathbf{2} \mathbf{M C} \mathbf{H}^{+}$is still very low. However, at the end of the titration it is seen that the main absorption band is centered at 417 $\mathrm{nm}$ for 1 and $423 \mathrm{~nm}$ for 2 . These absorption bands are red-shifted by ca. $10 \mathrm{~nm}$ compared to $\mathbf{1 M C H}^{+}$and $\mathbf{2} \mathbf{M C H}{ }^{+}$. This shows that with an increasing DNA concentration, the solutions are gradually enriched in DNA-bound $\mathbf{1 M C H}^{+}\left(\mathbf{1} \mathbf{M C H}^{+} @ \mathbf{D N A}\right)$ and $\mathbf{2} \mathbf{M C H}$ (2MCH+ @DNA) at the expense of mainly 1MC and 2MC (vide infra).

Finally, at pH 5 there are substantial amounts of $\mathbf{1} \mathbf{M C H}{ }^{+}$and $\mathbf{2} \mathbf{M C H} \mathbf{H}^{+}$present before DNA addition, as the $\mathrm{pH}$ is close to the $\mathrm{p} K_{\mathrm{a}}$-values in solution. The spectral changes parallel those 
observed at $\mathrm{pH}$ 6: A gradual red-shift in the absorption of the $\mathrm{MCH}^{+}$forms around $400 \mathrm{~nm}$ and a concomitant decrease in the absorption of the $\mathrm{MC}$ forms at longer wavelengths.

With the titration data between $\mathrm{pH} 5$ and $\mathrm{pH} 9$ at hand, it is obvious that the $\mathrm{p} K_{\mathrm{a}}$-value of the $\mathrm{MCH}^{+}$form for 1 and 2 must experience an increase when bound to DNA. This is most evident at $\mathrm{pH}$ 6, where the $\mathrm{MC} / \mathrm{MCH}^{+}$equilibrium favors $\mathrm{MC}$ before addition of DNA (in accordance with the $\mathrm{p} K_{\mathrm{a}}$-values free in solution of 5.2 and 4.8$)$. As saturation is approached in the DNA titration, the equilibrium is shifted to contain mostly $\mathrm{MCH}^{+} @ \mathrm{DNA}$. Moreover, the observation of isosbestic points in the spectra may at first seem unexpected, as four species are present in the solutions for both 1 and 2 (neglecting SP): $\mathrm{MC}, \mathrm{MCH}^{+}, \mathrm{MC} @ \mathrm{DNA}$, and $\mathrm{MCH}^{+} @$ DNA. However, as the ratio $[\mathrm{MC}] /\left[\mathrm{MCH}^{+}\right]$as well as the ratio [MC@DNA]/[MCH $\mathrm{MDNA}^{+}$are constant at each pH (the ratios for each pH being determined by the $\mathrm{p} K_{\mathrm{a}}$ in solution and the $\mathrm{p} K_{\mathrm{a}}$ when bound to DNA), there are only two "apparent" or "effective" absorption spectra at each $\mathrm{pH}$. These spectra are linear combinations of, respectively, the $\mathrm{MC}+\mathrm{MCH}^{+}$spectra and the $\mathrm{MC} @ \mathrm{DNA}+\mathrm{MCH}^{+} @ \mathrm{DNA}$ spectra. As we never reached full saturation in the binding titrations, the absorption spectra of the fully bound species MC@DNA at pH 9 and $\mathrm{MCH}^{+} @ \mathrm{DNA}$ at pH 5 were extrapolated from the titration data by singular value decomposition (SVD) analysis in combination with a 1:1 independent binding-site model. These spectra are displayed in Figure 5 together with the experimentally recorded spectra of $\mathrm{MC}$ and $\mathrm{MCH}^{+}$. 


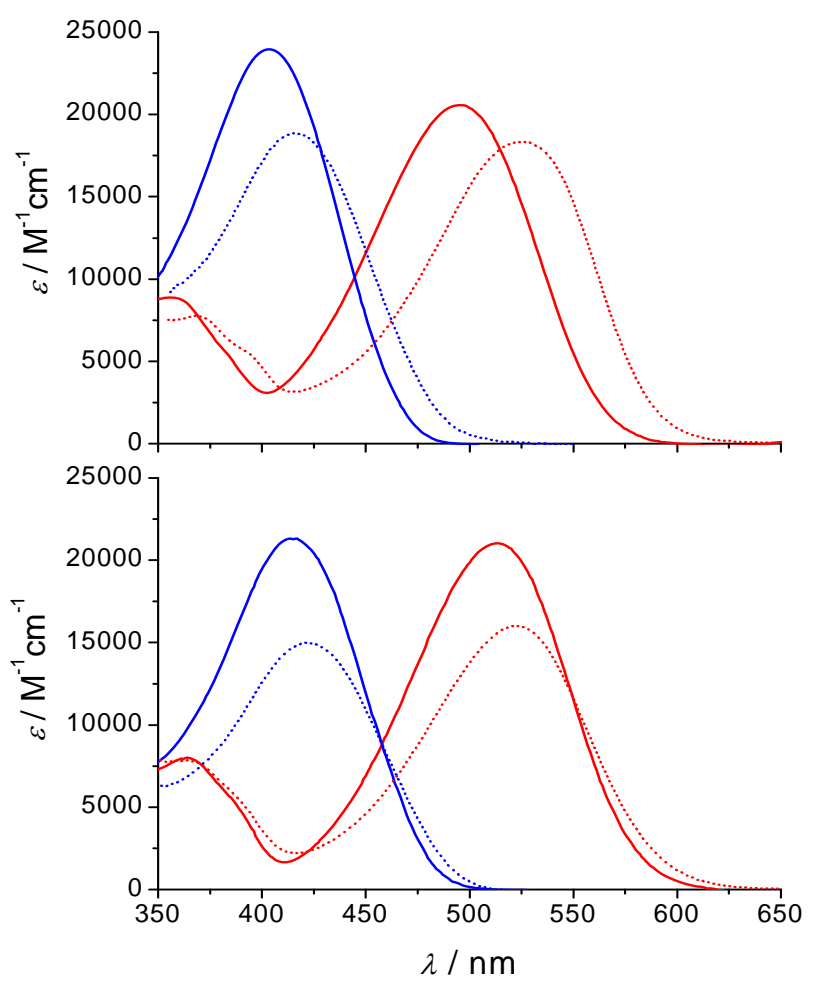

Figure 5. Absorption spectra of $\mathrm{MC}$ (red solid lines), $\mathrm{MCH}^{+}$(blue solid lines) as well as the spectra of MC@DNA (red dotted lines) and $\mathrm{MCH}^{+} @ \mathrm{DNA}$ (blue dotted lines) derived from extrapolation of the titration data. The spectra of $\mathbf{1}$ are shown in the top panel, and the spectra of 2 are shown in the bottom panel.

The spectra of the DNA-bound forms are red-shifted compared to the spectra in solution, a commonly observed feature for DNA-binding species. With the spectra of MC@DNA and $\mathrm{MCH}^{+} @ \mathrm{DNA}$ at hand, we could determine the ratio [MC@DNA]/[MCH+@DNA] at saturation (extrapolated absorption spectra, vide supra) at every $\mathrm{pH}$ by linear combinations. The results are shown in Table 1. This information made it possible to determine $\mathrm{pK}_{\mathrm{a}}^{\mathrm{DNA}}$, i.e., the $\mathrm{p} K_{\mathrm{a}}$-value of $\mathrm{MCH}^{+} @ \mathrm{DNA}$. The values are 6.7 for 1, and 6.6 for 2. Furthermore, assuming $\mathrm{MC}$ to be the exclusive DNA-binder at $\mathrm{pH} 9$ (a fair approximation given the $\mathrm{p} K_{\mathrm{a}}^{\mathrm{DNA}}$-values of 6.6 and 6.7 for $\mathbf{1}$ and 2), we fitted the binding isotherms at this $\mathrm{pH}$ to a non- 
linear expression to get the binding constants of $\mathrm{MC}, K_{\mathrm{MC}}{ }^{[34]}$ The resulting values are $9.9 \times 10^{2}$ $\mathrm{M}^{-1}$ and $4.2 \times 10^{3} \mathrm{M}^{-1}$ for $\mathbf{1}$ and $\mathbf{2}$, respectively.

Assuming separate non-cooperative binding for $\mathrm{MC}$ and $\mathrm{MCH}^{+}$, the acidity constants $K_{\mathrm{a}}$ and the binding constants $K$ are cyclically connected according to the 4-state model shown in Scheme 2.

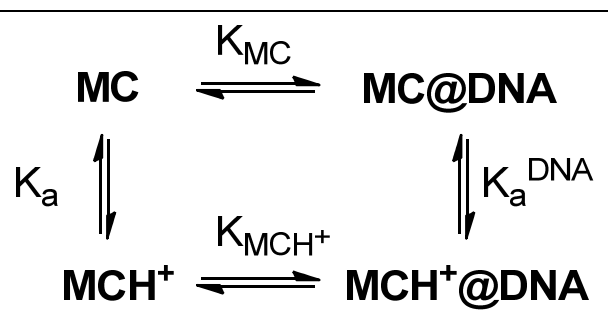

Scheme 2. The 4-state model including the acidity constants $\left(K_{\mathrm{a}}\right.$ and $\left.K_{\mathrm{a}}^{\mathrm{DNA}}\right)$ and the binding constants $\left(K_{\mathrm{MC}}\right.$ and $\left.\mathrm{K}_{\mathrm{MCH}}+\right)$ of the relevant forms.

From this model, the following relation between the binding constants and the $\mathrm{p} K_{\mathrm{a}}$-values can be derived.

$$
\frac{K_{M C}}{K_{M C H^{+}}}=10^{p K_{a}-p K_{a}{ }^{D N A}}
$$

where $K_{\mathrm{MC}}$ and $\mathrm{K}_{\mathrm{MCH}}{ }^{+}$are the binding constants of the $\mathrm{MC}$ and $\mathrm{MCH}^{+}$forms, whereas $\mathrm{p} K_{\mathrm{a}}$ and $\mathrm{p} K_{\mathrm{a}}^{\mathrm{DNA}}$ are the $\mathrm{p} K_{\mathrm{a}}$-values of $\mathrm{MCH}^{+}$in solution and $\mathrm{MCH}^{+} @ \mathrm{DNA}$. With $\mathrm{p} K_{\mathrm{a}}, \mathrm{p} K_{\mathrm{a}}^{\mathrm{DNA}}$, and $K_{\mathrm{MC}}$ known, $K_{\mathrm{MCH}}+$ is determined from eq. 2 . The derived values are $3.4 \times 10^{4} \mathrm{M}^{-1}$ and $2.8 \times 10^{5} \mathrm{M}^{-1}$ for 1 and 2 (see Table 1), i.e., the protonated forms $\mathrm{MCH}^{+}$bind, respectively, 35 and 66 times stronger to DNA compared to the non-protonated MC forms. It is also seen that 2 binds significantly stronger than $\mathbf{1}$ in both the $\mathrm{MC}$ and the $\mathrm{MCH}^{+}$form, although the effect is less pronounced (increase by a factor of 4 and 8 , respectively). This is depicted in Scheme 3. It is obvious that the addition of an extra positive charge to the phenolate group (due to 
protonation of the phenolate oxygen) has a much more pronounced effect compared to the addition of a positively charged aminopropyl tail to the indolenium nitrogen. Another observation of the same effect is that the MC form of $\mathbf{1}$ binds significantly to DNA, whereas no binding is observed for the MC form of $\mathbf{3}$ and $\mathbf{4}$ (see Scheme 1).

Table 1. $\mathrm{p} K_{\mathrm{a}}$-values and binding constants $K$ for $\mathbf{1}$ and 2 together with the ratio $\left[\mathrm{MCH}^{+} @ \mathrm{DNA}\right] /[\mathrm{MC} @ \mathrm{DNA}]$ at different $\mathrm{pH}$. The numbers in parenthesis are the results from the fit using the global McGhee-von Hippel model with the nearest neighbor exclusion ( $n=2$, see text below for details).

\begin{tabular}{c|cc}
\multicolumn{1}{c}{$\mathbf{1}$} & $\mathbf{2}$ \\
\hline $\mathrm{p} K_{\mathrm{a}}$ & 5.2 & 4.8 \\
$\mathrm{p} K_{\mathrm{a}}^{\mathrm{DNA}}$ & $6.7(6.8)$ & $6.6(6.6)$ \\
$K_{\mathrm{MC}}\left(\mathrm{M}^{-1}\right)$ & $9.9 \times 10^{2}\left(1.2 \times 10^{3}\right)$ & $4.2 \times 10^{3}\left(2.4 \times 10^{3}\right)$ \\
$K_{\mathrm{MCH}}+\left(\mathrm{M}^{-1}\right)$ & $3.4 \times 10^{4}\left(4.8 \times 10^{4}\right)$ & $2.8 \times 10^{5}\left(1.5 \times 10^{5}\right)$ \\
{$\left[\mathrm{MCH}^{+} @ \mathrm{DNA}\right] /[\mathrm{MC} @ \mathrm{DNA}]$ at $\mathrm{pH} 6$} & $91 / 9$ & $-{ }^{\mathrm{a}}$ \\
{$\left[\mathrm{MCH}^{+} @ \mathrm{DNA}\right] /[\mathrm{MC} @ \mathrm{DNA}]$ at $\mathrm{pH} 7$} & $34 / 66$ & $28 / 72$ \\
{$\left[\mathrm{MCH}^{+} @ \mathrm{DNA}\right] /[\mathrm{MC} @ \mathrm{DNA}]$ at $\mathrm{pH} 8$} & $8 / 92$ & $4 / 96$
\end{tabular}

\footnotetext{
${ }^{\text {a }}$ Data omitted due to negative absorbance values in the extrapolated spectrum at saturation. See text for details.
} 


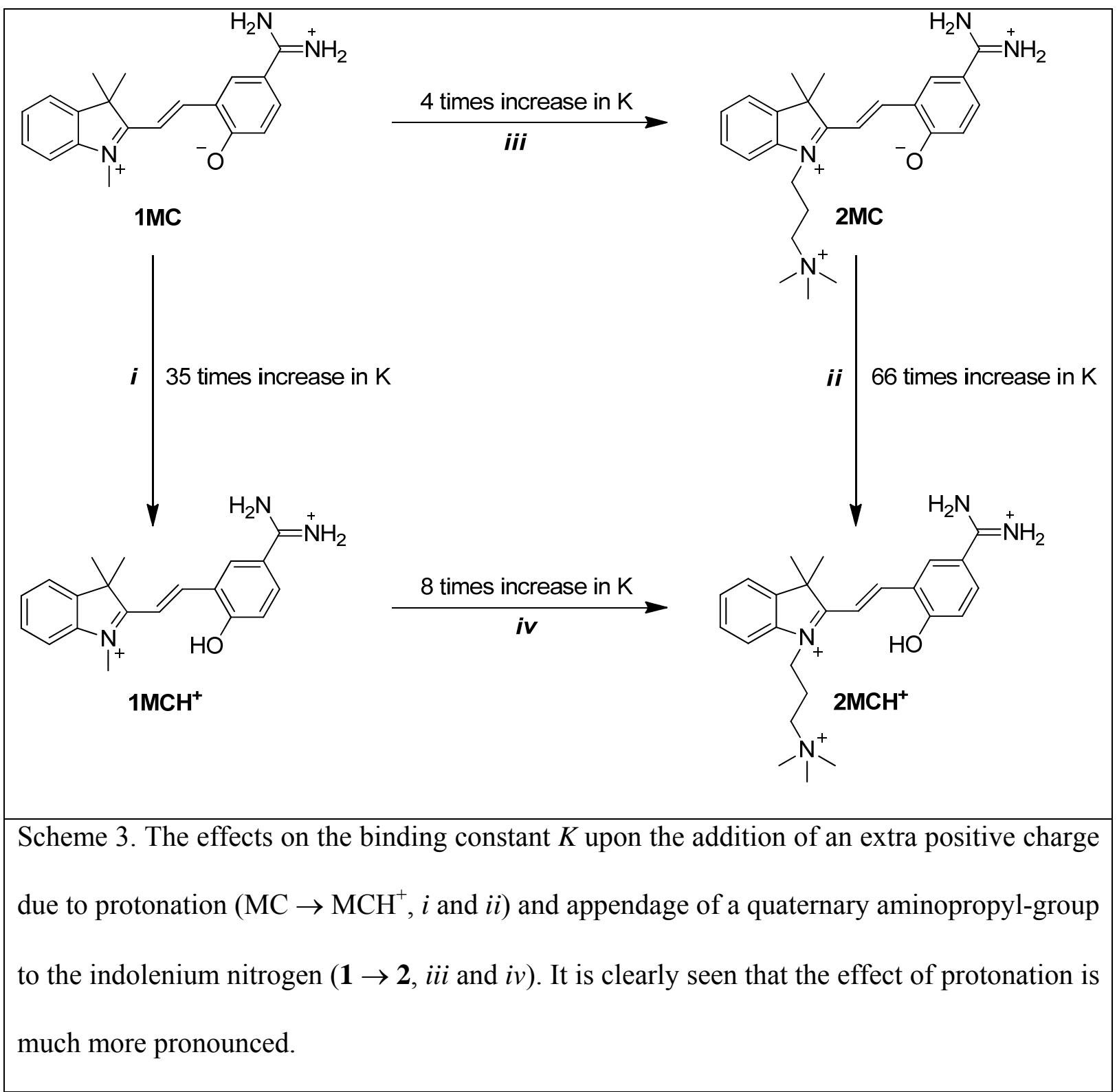

A likely explanation is that the $\mathrm{MC}$ chromophore is a zwitterion, whereas $\mathrm{MCH}^{+}$is not. Hence, in the non-polar milieu experienced upon DNA-binding, the MC form is less stabilized due to the polar nature of the zwitterion, and the effect of any appended positively charged aminopropyl-group is of minor importance for the binding constant.

To verify the 4-state model shown in Scheme 2, a theoretical binding isotherm based on the McGhee-von Hippel method was globally fitted to all titration data between $\mathrm{pH} 5$ and $\mathrm{pH} 9$ with the use of SVD. ${ }^{[35-36]}$ For all titration series, the third singular value was clearly 
insignificant, in good agreement with the observed sharp isosbestic points, and the notion about two "effective" species in the absorption spectra at each pH. With this approach we also take into account the binding site coverage $(n)$ at the DNA as well as any cooperative factors. Hence, this may provide additional insight into the binding features. By fitting the two significant SVD-components of the absorption spectra, the overall binding constant as well as $\mathrm{p} K_{\mathrm{a}}^{\mathrm{DNA}}$ could be verified with $n=2$. The calculated binding constants and $\mathrm{p} K_{\mathrm{a}}$-values (see values in parenthesis in Table 1) are in good agreement with the same numbers obtained using the initial independent binding site model described above. No cooperative effects were indicated from the fitting. Hence, we can conclude our model to be valid and that the DNAaffinity of $\mathbf{1 M C}, \mathbf{1} \mathbf{M C H}{ }^{+}, \mathbf{2 M C}$, and $\mathbf{2} \mathbf{M C H}^{+}$are well-established.

Flow oriented linear dichroism for binding mode determination: In order to get information about the binding mode of the different forms of $\mathbf{1}$ and 2, flow-oriented linear dichroism (LD) measurements were undertaken. ${ }^{[37]}$ Here, the DNA molecules are aligned in a shear flow so that any species that bind to DNA with a non-random orientation (and not close to the magic angle $54.7^{\circ}$ ) will display an LD signal. LD is defined as $A_{\|}-A_{\perp}$ where $A_{\|}$and $A_{\perp}$ are the absorbances of light polarized parallel and perpendicular to the orientation axis (here the DNA helix-axis), respectively. Hence, chromophores that bind to DNA with the transition moments oriented more parallel to the helix axis will display positive $L D$, whereas a perpendicular orientation will result in a negative LD. The results from $\mathrm{pH} 6$ and $\mathrm{pH} 8$ are displayed in Figure 6. The samples were exposed to UV light to trigger the isomerization to the $\mathrm{MC} / \mathrm{MCH}^{+}$forms before each measurement. 


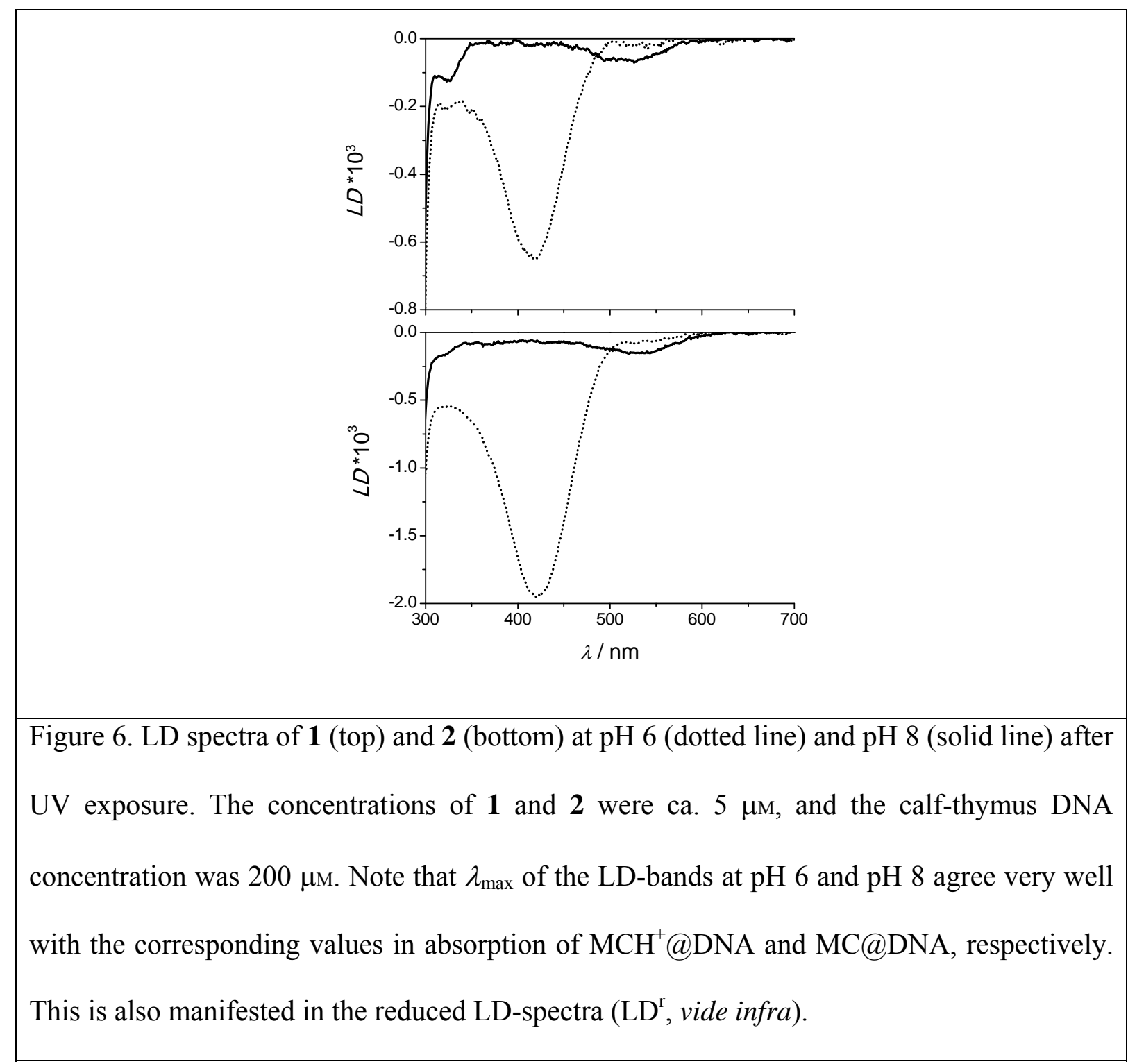

At $\mathrm{pH}$ 6, where the majority of the DNA-binding is ascribed to $\mathbf{1} \mathbf{M C} \mathbf{H}^{+}$and $\mathbf{2} \mathbf{M C} \mathbf{C H}^{+}$, negative LD bands are observed in wavelength regions in good agreement with the absorption spectra of 1MCH $\mathbf{M C D N A}^{+}$and $\mathbf{2} \mathbf{M C H}^{+} @$ DNA. At pH 8, these bands are replaced for negative bands at wavelengths corresponding to the absorption spectra of 1MC@DNA and 2MC@DNA Hence, the LD results clearly complement the changes in the absorption spectra upon DNA addition described above (see Figures 3-5).

A negative LD band is a typical signal for intercalative binding, i.e., the DNA-binding molecule is inserted in a sandwich-like fashion between the DNA base pairs. Hence, the 
transition dipole moments of the DNA-intercalator and the DNA-bases are oriented in parallel with an angle of ca. $90^{\circ}$ to the helix axis. The actual binding angle can be determined experimentally from the reduced LD $\left(\mathrm{LD}^{\mathrm{r}}\right)$, which is the LD spectrum divided by the isotropic absorption spectrum $\left(A^{\text {iso }}\right)$ and is related to the binding angle $\alpha$ according to

$$
L D^{r}=\frac{L D}{A^{i s o}}=\frac{3}{2} S\left(3 \cos ^{2} \alpha-1\right)
$$

Here, $S$ is the orientation factor describing the degree of sample orientation. As the DNAbases have an angle of $90^{\circ}$ to the helix axis, the orientation factor is easily determined from the $\mathrm{LD}^{\mathrm{r}}$ of the DNA bases, which allows for determination of also the binding angle $\alpha$ of the bound species. ${ }^{[38]}$

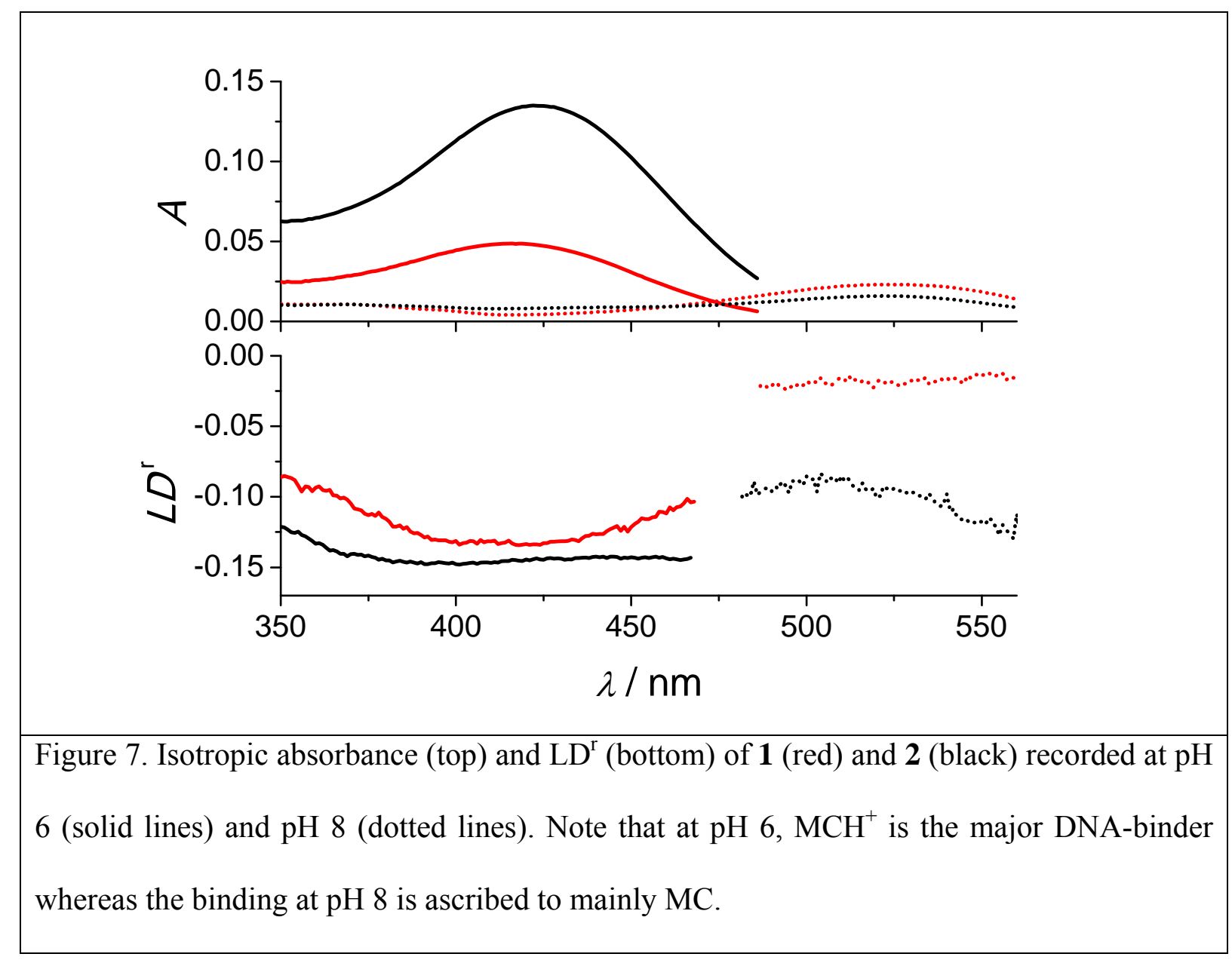


The LD $^{\mathrm{r}}$ bands shown in Figure 7 are fairly constant over the absorption bands which indicates a single binding mode for each of the bound species. The $\mathrm{LD}^{\mathrm{r}}$-values for $\mathbf{1} \mathbf{M C} \mathbf{H}^{+}$, 2MC, and $\mathbf{2} \mathbf{M C H}^{+}$are very similar $(-0.10$ to -0.15$)$ which indicates a common binding mode for all of these forms. With this value, the calculated angle is $65-70^{\circ}$ which suggests a slightly tilted intercalation binding mode, rather than groove binding which typically is manifested in positive $\mathrm{LD}^{\mathrm{r}}$-values. The $\mathrm{LD}^{\mathrm{r}}$ of $\mathbf{1 M C}$ is, however, much lower (ca. -0.02) which indicates a binding mode with the transition dipole oriented very close to the magic angle where no LD can be seen. Most likely, 1MC does not intercalate but instead finds a stable environment on the outside of the helix. A separate binding mode for 1MC is also suggested by the dramatic red-shift in the absorbance observed upon binding (see Figure 5). 1MC is red-shifted by 31 $\mathrm{nm}$, whereas the corresponding number for $\mathbf{2 M C}$ is only $9 \mathrm{~nm}$. The difference between $\mathbf{1 M C}$ and 2MC is the extra charge on 2MC from the appended quaternary aminopropyl tail. 2MC is in fact closely related to $\mathbf{3} \mathbf{M C H} \mathbf{H}^{+}$and $\mathbf{4} \mathbf{M C H}{ }^{+}$, both known to bind to DNA by intercalation, ${ }^{[9,14]}$ with respect to structure and charge distribution (see Scheme 1). It is therefore expected that they would display a similar binding mode, which is indeed observed. This indicates that the aminopropyl tail assists the intercalation of the phenolate part, most likely because it resides in close proximity to the negative backbone of DNA. Without this positively charged tail, the stabilization disappears and the phenolate part is further away from the base pairs. This may rationalize the difference in binding mode between $\mathbf{1 M C}$ and $\mathbf{2 M C}$. Furthermore, protonation of $\mathbf{1 M C}$ to form $\mathbf{1} \mathbf{M C H}{ }^{+}$eliminates the zwitterionic character. As mentioned above, this will increase the affinity for more hydrophobic milieus, and it is therefore likely that $\mathbf{1} \mathbf{M C H}{ }^{+}$is a better suited intercalator than $\mathbf{1 M C}$. 


\section{Conclusions}

We have synthesized two photochromic amidine substituted spiropyran derivatives (1 and 2$)$ and characterized their DNA binding properties. The results show that the closed spiro form SP does not bind significantly to DNA, whereas the open merocyanine isomer binds in both its non-protonated form $\mathrm{MC}$ and in its protonated form $\mathrm{MCH}^{+}$, the latter being the stronger binder by a factor of ca. 50. It is also concluded that a single intercalative binding mode with binding constants of $10^{4}-10^{5} \mathrm{M}^{-1}$ is observed for the $\mathrm{MCH}^{+}$forms. The weaker binding observed for the $\mathrm{MC}$ form of $\mathbf{2}$ is also ascribed to intercalation, whereas the corresponding form of $\mathbf{1}$ binds with an orientation close to the magic angle. The differences in binding constants and binding modes for the various species are explained by structural and charge distribution arguments. 


\section{Experimental Section}

Materials: The synthesis of $\mathbf{1}$ have been described earlier, ${ }^{[21]}$ whereas the synthesis of $\mathbf{2}$ is outlined in the Supporting Information. To obtain absorption spectra of the pure open forms $\left(\mathrm{MC}\right.$ and $\left.\mathrm{MCH}^{+}\right)$the SP isomer was heated in an aqueous solution at $\mathrm{pH} 1$ until the sample was fully converted to the $\mathrm{MCH}^{+}$form (ca. $5 \mathrm{~min}$ ). For $\mathrm{MC}$, this was followed by neutralization of the $\mathrm{pH}$ using $\mathrm{NaOH}$. All experiments with DNA were performed in aqueous solution contaning $10 \mathrm{~mm} \mathrm{NaCl}$ buffered with $10 \mathrm{~mm}$ of $\mathrm{Na}_{2} \mathrm{HPO}_{4} / \mathrm{NaH}_{2} \mathrm{PO}_{4}$ buffers set to $\mathrm{pH}$ 5.0, 6.0, 7.0, 8.0, and $\mathrm{pH}$ 9.0. The buffers were set by mixing $\mathrm{Na}_{2} \mathrm{HPO}_{4}$ and $\mathrm{NaH}_{2} \mathrm{PO}_{4}$ in different ratio and the $\mathrm{pH}$ was adjusted by droplets of $0.1 \mathrm{~m} \mathrm{NaOH}$ or $0.1 \mathrm{~m} \mathrm{HCl}$. Salmonsperm DNA (used in the titration experiments) and calf-thymus DNA (used in the LD measurements) were purchased from Sigma. Before spectroscopic measurments, the calfthymus DNA samples were dissolved in buffer sollutions ( $\mathrm{pH} 6.0$ and $\mathrm{pH} 7.0$ ) and filterd through Minisart-GF prefilter.

Photophysical measurements: Ground state absorption spectra were recorded on a Cary 5000 spectrometer. LD was measured using a Chirascan LD spectropolarimeter, equipped with an Oxley prism to obtain linerarly polarized light, on samples oriented in an outerrotating Couette flow cell with $1 \mathrm{~mm}$ path length. Spectra were measured at a shear gradient of $3000 \mathrm{~s}^{-1}$ and corrected for basline contribution by subtraction of the corresponding spectra recorded without rotation. The photoinduced isomerization reactions were performed using a UVP lamp model UVGL-25 (254 nm) or a $500 \mathrm{~W}$ Xe lamp equipped with a hot mirror $(A=1.8$ at $900 \mathrm{~nm}$ ) to reduce IR intensity and suitable optical filters. For isomerization quantum yield determinations, a hand held CW SDLaser 301 at $532 \mathrm{~nm}$ was used (see Supporting Information for details). The samples were continously stirred during all irradiation processes. 


\section{Acknowledgements}

This work was financed by the Swedish Research Council (Grant 622-2010-280) and the European Research Council (ERC FP7/2007-2013 Grant No. 203952).

\section{References}

[1] A. A. Beharry, G. A. Woolley, Chem. Soc. Rev. 2011, 40, 4422-4437.

[2] C. Brieke, F. Rohrbach, A. Gottschalk, G. Mayer, A. Heckel, Angew. Chem. 2012, 124, 85728604; Angew. Chem. Int. Ed. 2012, 51, 8446-8476.

[3] R. Göstl, A. Senf, S. Hecht, Chem. Soc. Rev. 2014, 43, 1982-1996.

[4] D. D. Young, A. Deiters, Org. Biomol. Chem. 2007, 5, 999-1005.

[5] J. Zhang, J. Wang, H. Tian, Mater. Horiz. 2014, 1, 169-184.

[6] W. Szymański, J. M. Beierle, H. A. V. Kistemaker, W. A. Velema, B. L. Feringa, Chem. Rev. 2013, $113,6114-6178$

[7] P. B. Dervan, Bioorg. Med. Chem. 2001, 9, 2215-2235.

[8] S. M. Nelson, L. R. Ferguson, W. A. Denny, Mutat. Res. 2007, 623, 24-40.

[9] J. Andersson, S. M. Li, P. Lincoln, J. Andréasson, J. Am. Chem. Soc. 2008, 130, 11836-11837.

[10] A. Basak, D. Mitra, M. Kar, K. Biradha, Chem. Commun. 2008, 3067-3069.

[11] D. Berdnikova, O. Fedorova, E. Gulakova, H. Ihmels, Chem. Commun. 2012, 48, 4603-4605.

[12] M. L. Di Pietro, F. Puntoriero, F. Tuyéras, P. Ochsenbein, P. P. Lainé, S. Campagna, Chem. Commun. 2010, 46, 5169-5171.

[13] C. Dohno, T. Yamamoto, K. Nakatani, Eur. J. Org. Chem. 2009, 4051-4058.

[14] M. Hammarson, J. Andersson, S. M. Li, P. Lincoln, J. Andréasson, Chem. Commun. 2010, 46, $7130-7132$

[15] H. Ihmels, J. Mattay, F. May, L. Thomas, Org. Biomol. Chem. 2013, 11, 5184-5188.

[16] A. Mammana, G. T. Carroll, J. Areephog, B. L. Feringa, J. Phys. Chem. B 2011, 115, 1158111587. 
[17] T. C. S. Pace, V. Müller, S. M. Li, P. Lincoln, J. Andréasson, Angew. Chem. 2013, 125, 44894492; Angew. Chem. Int. Ed. 2013, 52, 4393-4396.

[18] S. V. Paramonov, V. Lokshin, H. Ihmels, O. A. Fedorova, Photochem. Photobiol. Sci. 2011, $10,1279-1282$

[19] M. I. Sánchez, O. Vázquez, M. E. Vázquez, J. L. Mascareñas, Chem. Commun. 2011, 47, 11107-11109.

[20] F. Jonsson, T. Beke-Somfai, J. Andréasson, B. Nordén, Langmuir 2013, 29, 2099-2103.

[21] J. R. Nilsson, C. P. Carvalho, S. M. Li, J. P. Da Silva, J. Andréasson, U. Pischel, ChemPhysChem 2012, 13, 3691-3699.

[22] J. R. Nilsson, S. M. Li, B. Önfelt, J. Andréasson, Chem. Commun. 2011, 47, 11020-11022.

[23] H. Ihmels, L. Thomas, in Materials Science of DNA chemistry (Ed.: J. I. Jin), CRC Press, Boca Raton, 2011, pp. 49-75.

[24] S. Ozden, D. Atabey, S. Yildiz, H. Goker, Bioorg. Med. Chem. 2005, 13, 1587-1597.

[25] W. D. Wilson, F. A. Tanious, D. Y. Ding, A. Kumar, D. W. Boykin, P. Colson, C. Houssier, C. Bailly, J. Am. Chem. Soc. 1998, 120, 10310-10321.

[26] K. C. Gross, P. G. Seybold, Int. J. Quantum Chem. 2001, 85, 569-579.

[27] Destabilization of the negatively charged phenolate ion of MC by the introduction of a less electron withdrawing substituent in para-position will increase the corresponding $\mathrm{p} K_{\mathrm{a}}$-value. At the same time, it will increase the rate of the thermal isomerization to the SP isomer. Hence, there is a trade-off between a high $\mathrm{pK}$-value for $\mathrm{MCH}^{+}$and good thermal stability of MC.

[28] R. C. Bertelson, in Organic Photochromic and Thermochromic Compounds, Vol. 1 (Eds.: J. C. Crano, R. J. Guglielmetti), Plenum Press, New York, 1998, pp. 11-83.

[29] Y. Shiraishi, M. Itoh, T. Hirai, Phys. Chem. Chem. Phys. 2010, 12, 13737-13745.

[30] T. Stafforst, D. Hilvert, Chem. Commun. 2009, 287-288.

[31] M. Hammarson, J. R. Nilsson, S. M. Li, T. Beke-Somfai, J. Andréasson, J. Phys. Chem. B 2013, 117, 13561-13571. 
[32] Due to the subsequent hydrolysis of the MC form, the thermal equilibrium establishment between SP and MC is to be considered as a pre-equilibrium.

[33] At pH of ca. 3 or lower, protonation of the SP isomer also occurs. This is, however, not relevant for the studies performed here as the lowest $\mathrm{pH}$ used is 5 .

[34] P. Thordarson, Chem. Soc. Rev. 2011, 40, 1305-1323.

[35] M. Kubista, R. Sjöback, B. Albinsson, Anal. Chem. 1993, 65, 994-998.

[36] J. D. McGhee, P. H. V. Hippel, J. Mol. Biol. 1974, 86, 469-489.

[37] B. Nordén, F. Tjerneld, Biophys. Rev. 1976, 4, 191-198.

[38] B. Nordén, M. Kubista, T. Kurucsev, Q. Rev. Biophys. 1992, 25, 51-170. 